\title{
Some interesting isolates from a diagnostic laboratory
}

\author{
P. L. LIM ${ }^{1}$ \\ From the Pathology Department, General Hospital, Penang, Malaysia
}

SUMMARY Citrobacter koseri, Plesiomonas shigelloides, Edwardsiella tarda, Yersinia enterocolitica, Alkalescens dispar, Vibrio parahaemolyticus, and Vibrio alginolyticus were seven interesting microorganisms isolated recently in our diagnostic laboratory.

Penang is not only a paradise for tourists but also for the microbe hunters. I briefly report here the isolation and characterisation of some of the more recently described bacteria.

\section{Material and methods}

The isolation and identification methods were mostly conventional (Edwards and Ewing, 1972; Blair et al., 1970). Pathotec-strips (Warner-Lambert) were used in addition to supplement reactions for nitrate reduction, aesculin hydrolysis, and malonate utilisation, while the API system (Analytab Products Inc) was used to supplement reactions for betagalactosidase, gelatin, arginine dihydrolase, ornithine decarboxylase, amygdalin, melibiose, and sorbitol (the other reactions in the set were read only against those by conventional methods). Motility was observed in both the hanging-drop and semi-solid agar at $37^{\circ} \mathrm{C}$. Motility was also observed at $25^{\circ} \mathrm{C}$ for Yersinia enterocolitica. For Vibrio parahaemolyticus and $V$. alginolyticus the conventional sugar media, including the tryptone water (for indole production and motility), the MR-VP medium, and the lysine decarboxylase medium-but not the triple sugar iron agar and Koser's citrate medium-were supplemented with $2 \%$ sodium chloride.

\section{CITROBACTER KOSERI}

Eight strains of $C$. koseri (Rowe et al, 1975) were isolated on both MacConkey's and human blood agar-

\footnotetext{
${ }^{1}$ Present address: Department of Microbiology and Immunology, University of Adelaide, Adelaide, South Australia
}

Received for publication 30 August 1977 two in pure and significant growth from cases of urinary tract infection in adults, two of doubtful significance in mixed culture from sputum, and another two in pure and heavy growth from pus of infected wounds. It was also isolated in pure and heavy growth from a case of eye discharge since birth in a 2-monthold baby (no gonococcus was found) and from a case of otitis media. The biochemical characteristics of these strains are shown in the Table. Their notable features are the positive reactions for indole, malonate, adonitol, and ornithine decarboxylase and the negative reactions for hydrogen sulphide, lysine decarboxylase, and potassium cyanide. They were all sensitive to tetracycline $(10 \mu \mathrm{g})$, chloramphenicol (10 $\mu \mathrm{g})$, streptomycin $(10 \mu \mathrm{g})$, and cephalothin $(10 \mu \mathrm{g})$ but resistant to ampicillin $(25 \mu \mathrm{g})$.

\section{PLESIOMONAS SHIGELLOIDES}

Three isolates of $\boldsymbol{P}$. shigelloides were found in cases of acute gastroenteritis in adults where the common enteropathogens were absent. These were isolated from stool on direct deoxycholate agar. Another strain was isolated from the stool of a healthy laboratory worker on thiosulphate citrate bile salt (TCBS) agar after overnight enrichment in alkaline peptone water during a screen for carriers of salmonella and Vibrio cholerae. It was also isolated in pure culture on both MacConkey and human blood agar from the ear of a 19-year-old man who had otorrhoea after mastoidectomy. All strains were positive for oxidase, indole, citrate, lysine decarboxylase, and inositol but negative for urease and mannitol. Lactose was not fermented on the first day but three strains fermented it 1-2 days later. They were all motile and produced an acid butt and alkaline slope with no gas or hydrogen sulphide in the triple sugariron agar. Two of the strains were characterised in greater detail, as shown in the Table. 
Table Biochemical reactions of seven isolates at $37^{\circ} \mathrm{C}$ showing number of positive strains. Figures in parentheses shov number of strains positive after two to three days

\begin{tabular}{|c|c|c|c|c|c|c|c|}
\hline Test/substrate & C. koseri & P. shigelloides & E. tarda & $\begin{array}{l}Y . \\
\text { enterocolitica }\end{array}$ & A. dispar & $\begin{array}{l}\text { V. } \\
\text { parahaemolyticus* }\end{array}$ & $\begin{array}{l}\text { V. } \\
\text { alginolyticus* }\end{array}$ \\
\hline $\begin{array}{l}\text { Hydrogen sulphide } \\
\text { (TSI) }\end{array}$ & $0(0)$ & $0(0)$ & 1 & $0(0)$ & $0(0)$ & $0(0)$ & $0(0)$ \\
\hline Indole (Kovac's) & 8 & 2 & 1 & 1 & 1 & 2 & 1 \\
\hline Urease & $0(0)$ & $0(0)$ & $0(0)$ & 1 & $0(0)$ & $0(0)$ & $0(0)$ \\
\hline Motility & 8 & 2 & 1 & $0 \dagger$ & 0 & 2 & 1 \\
\hline Lysine decarboxylase & $0(0)$ & 2 & 1 & $0(0)$ & $0(0)_{+}^{+}$ & 2 & 1 \\
\hline Arginine dihydrolase & 4 & 2 & 0 & 0 & 0 & 0 & 0 \\
\hline $\begin{array}{l}\text { Ornithine } \\
\text { decarboxylase }\end{array}$ & 8 & 2 & 1 & 1 & 0 & 2 & 0 \\
\hline Citrate (Koser's) & 8 & 0 & 0 & 1 & 0 & $0_{+}^{+}$ & $0_{+}^{+}$ \\
\hline Methyl red & 8 & ND & 1 & $0 \S$ & ND & 2 & 1 \\
\hline Voges-Proskauer & 0 & 0 & 0 & $0 \S$ & ND & 0 & 1 \\
\hline Gelatin & 0 & 0 & 0 & 0 & 0 & 2 & 1 \\
\hline Bəta-galactosidase & 8 & 2 & 0 & 0 & 1 & 0 & ND \\
\hline $\begin{array}{l}\text { Phenylalanine } \\
\text { deaminase }\end{array}$ & 0 & 0 & 0 & 0 & 0 & 0 & 0 \\
\hline Oxidase & 0 & 2 & 0 & 0 & 0 & 2 & 1 \\
\hline Catalase & 8 & 2 & 1 & ND & ND & ND & ND \\
\hline Nitrate reduction & 8 & 2 & ND & 1 & ND & 2 & 1 \\
\hline Amygladin & 8 & 0 & 0 & 0 & 0 & 0 & 0 \\
\hline Malonate & 8 & 0 & ND & 0 & ND & 0 & 0 \\
\hline Esculin & 0 & 0 & ND & 0 & ND & 0 & 0 \\
\hline $\mathrm{KCN}$ & 0 & ND & 0 & ND & ND & ND & ND \\
\hline Glucose (gas) & 8 & $0(0)$ & 1 & 1 & $0(0)$ & $0(0)$ & $0(0)$ \\
\hline Adonitol & 8 & $0(0)$ & $0(0)$ & $0(0)$ & $0(0)$ & $0(0)$ & $0(0)$ \\
\hline Arabinose & 8 & $0(0)$ & $0(0)$ & $0(1)$ & 1 & 2 & $0(0)$ \\
\hline Dulcitol & $3(0)$ & $0(0)$ & $0(0)$ & $0(0)$ & 1 & $0(0)$ & $0(0)$ \\
\hline Inositol & $0(2)$ & 2 & $0(0)$ & $0(0)$ & $0(0)$ & $0(0)$ & $0(0)$ \\
\hline Lactose & $0(4)$ & $0(1)$ & $0(0)$ & $0(0)$ & 1 & $0(0)$ & $0(0)$ \\
\hline Maltose & 8 & 2 & 1 & $0(0)$ & 1 & 2 & 1 \\
\hline Mannitol & 8 & $0(0)$ & $0(0)$ & $0(0)$ & 1 & 2 & 1 \\
\hline Mannose & 8 & $0(0)$ & 1 & 1 & 1 & 2 & 1 \\
\hline Melibiose & 0 & 0 & 0 & 1 & 1 & 0 & 0 \\
\hline Rhamnose & 8 & $0(0)$ & $0(0)$ & $0(0)$ & 1 & $0(0)$ & $0(0)$ \\
\hline Salicin & $0(6)$ & $0(0)$ & $0(0)$ & $0(0)$ & $0(0)$ & $0(0)$ & ND \\
\hline Sorbitol & 8 & 0 & 0 & 0 & 1 & 0 & 0 \\
\hline Sucrose & $0(0)$ & $0(0)$ & $0(0)$ & $0(0)$ & $0(0)$ & $0(0)$ & 1 \\
\hline $\begin{array}{l}\text { No. of strains } \\
\text { examined }\end{array}$ & 8 & 2 & 1 & 1 & 1 & 2 & 1 \\
\hline
\end{tabular}

*All conventional media (except TSI, urease, and Koser's citrate medium) supplemented with $2 \%$ sodium chloride. Bacterial suspension made in $0.85 \%$ saline for Pathotec strips.

+ Motile at $25^{\circ} \mathrm{C}$

†Positive in API set.

$\S$ Also negative at $25^{\circ} \mathrm{C}$

ND $=$ not done.

Out of three strains serologically examined one reacted strongly with Shigella boydii polyvalent 2 antiserum (Burroughs-Wellcome) (confirmed by Drs S. Ampalam and M. Jegathesan, Kuala Lumpur) while the other two did not agglutinate in any of the shigella antisera. This is a rare cross-reaction, because most of the strains isolated elsewhere (Cooper and Brown, 1968) possessed other shigella antigens-namely, those of Sh. sonnei. A more surprising finding (hitherto undisclosed) was that all three strains cross-reacted with Vibrio cholerae (El Tor, Inaba) (confirmed by Professor D. Rowley, Adelaide), which persisted after the organisms had been steamed for one hour. This cross-reaction with $V$. cholerae, which may be more important and common than the better known cross-reactions with shigella, should be looked for in future isolates.
EDWARDSIELLA TARDA

A strain of E. tarda (Ewing et al., 1965) was isolate from a 3-month-old baby, who was slightly dehy drated and had been passing watery stools for a week It was isolated on direct deoxycholate agar (withoun prior enrichment of the specimen) and mixed with \& predominance of coliforms, but no common enteroo pathogens were found. The main discriminator reactions of this strain are the indole and hydroge sulphide production and its inability to fermeno mannitol (Table). It was sensitive to tetracycline (10 $\mu \mathrm{g})$ and chloramphenicol $(10 \mu \mathrm{g})$.

YERSINIA ENTEROCOLITICA

A predominant growth of an organism resembling $Y \stackrel{\mathbb{Q}}{Q}$ enterocolitica was obtained from the sputum of a 58 year-old man who had chronic bronchitis and hypoo 
proteinaemia. It was isolated on both MacConkey and blood agar together with a smaller number of Klebsiella pneumoniae. The significance of its presence here was doubtful, particularly as it was not isolated again in a repeat culture. Its basic characteristics conform with that of $Y$. enterocolitica (Cowan, 1974)-namely, it was positive for urease, indole, and ornithine decarboxylase but negative for lysine, decarboxylase, and hydrogen sulphide (Table). Moreover, it was motile at $25^{\circ} \mathrm{C}$ but not at $37^{\circ} \mathrm{C}$. The Voges-Proskauer test, however, was negative at both temperatures. It was rather inert biochemically, utilising only glucose (with slight gas production), arabinose, mannose, melibiose, and xylose. However, Bottone et al. (1974) noted the difference between mesenteric and non-mesenteric isolates in their biochemical activities.

\section{ALKALESCENS DISPAR}

This anaerogenic, non-motile, indole-positive strain of $A$. dispar (Edwards and Ewing, 1972) was isolated from the floor of a maternity hospital. It was only superficially characterised (Table) but it agglutinated the specific antiserum for it (Burroughs-Wellcome). Its presence here was taken to suggest faecal contamination.

\section{VIBRIO PARAHAEMOLYTICUS AND}

\section{NON-CHOLERA VIBRIOS}

In 1974 there was a cholera outbreak (El Tor, Inaba) in Penang. It continued from May to December with a lull (no bacteriologically proved case) from August to October. Altogether 95 positive cases and 32 carriers were identified bacteriologically. Towards the end of the outbreak, in November, only eight cases were confirmed bacteriologically from 457 cases examined. (As a rule all hospitalised diarrhoeal cases were screened for $V$. cholerae because the disease caused by this bioserotype was relatively mild and difficult to distinguish from the other forms of gastroenteritis clinically.) However, during November many of the cholera-like cases were found to excrete $V$. parahaemolyticus and the other noncholera vibrios instead of $V$. cholera. This was similar to previous findings (Carpenter et al., 1965; Mudd, 1970) where $V$. cholerae could not be detected from many of the cholera-like cases and non-cholera vibrios were found in some (McIntyre $e t$ al., 1965). More noteworthy, the appearance of these vibrios in this instance at this time also marked the ending of the cholera outbreak.

From 20 of the diarrhoeal cases $(8$ females, 12 males; average age of both groups 24 years; range 3-52 years) a pure growth of a mucoid, non-sucrose fermenter was obtained on thiosulphate citrate bile salt sucrose (TCBS) agar after enrichment of the rectal swab in alkaline peptone water $(\mathrm{pH} \mathrm{8.4)} \mathrm{for} \mathrm{six}$ hours at $37^{\circ} \mathrm{C}$. This was also obtained from two asymptomatic contacts of cholera cases. This organism was later identified as $V$. parahaemolyticus (Chatterjee, 1975). On human blood agar it resembled a haemolytic, greyish-coloured coliform, unlike the greenish, haemolytic, and more translucent and coalescent colonies of $V$. cholerae on this agar. It was oxidase-positive and produced an alkaline slope and acid butt without gas or hydrogen sulphide in triple sugar iron agar. It failed to grow in the ordinary peptone water, which suggested a halophilic organism. Subsequently it was found that the organism could tolerate up to $8 \%$ sodium chloride in peptone water, with an optimum of around $3 \%$. It also failed to grow in the conventional Koser's citrate medium. Furthermore, all isolates were haemolytic on Wagatsuma agar (Miyamoto et al., 1969). They were positive for lysine decarboxylase, arabinose, mannitol, maltose, and mannose. Except for one strain they were negative for urease. They were sensitive to tetracycline $(10 \mu \mathrm{g})$ but resistant to ampicillin $(25 \mu \mathrm{g})$. The biochemical features of two of the isolates are detailed in the Table. In addition both strains were negative for the cholera-red and string tests. Of 18 strains sent for K-serotyping (by Dr M. Jegathesan) three belonged to group K VIII, two to group K I, two to group K II, and one reacted strongly with both $\mathrm{K}$ II and K VI antisera. The rest were not typable with the $\mathrm{K}$ antisera set (Toshiba Chemical Co, Tokyo).

In a routine examination of cooked and frozen prawns later two strains of $V$. parahaemolyticus were isolated. Except for the fermentation of arabinose they were identical with the human isolates in all the above characteristics (see Table) including their haemolysis on Wagatsuma agar. One of them belonged to group K IV and the other was not typable.

Not only were different serotypes of $V$. parahaemolyticus isolated towards the end of the cholera outbreak in November but other non-cholera vibrios were isolated-six from acute diarrhoeal cases and one from a carrier. Except for their variable reactions for arabinose and citrate they were identical with $V$. cholerae in all other biochemical aspects examined, including their morphology on human blood agar and TCBS agar and their darting motility. However, they were not agglutinable by anti- $V$. cholera antiserum (Burroughs-Wellcome) even after serial subculture (at least twice) on nutrient agar and steaming for one hour.

VIBRIO ALGINOLYTICUS

This marine bacterium (Ryan, 1976) was isolated from a sample of cooked, peeled, and frozen prawns on TCBS agar after overnight enrichment in alkaline 
peptone water. It differed from $V$. parahaemolyticus in being positive for sucrose and the Voges-Proskauer reaction and negative for arabinose (Table). In addition it grew in peptone water supplemented with $10 \%$ sodium chloride. It was non-haemolytic on Wagatsuma agar and negative for both the cholerared and string tests.

I thank the Director-General of Health, Malaysia, for permission to publish this paper, $\mathrm{Dr}$ C. Panicker for his enthusiasm, Drs $M$. Jegathesan and $\mathbf{S}$. Ampalam for help in the serological characterisation, and all members of the technical staff, including Kent Rogerson, for their excellent work. I also wish to thank Professor D. Rowley for reviewing the manuscript.

\section{References}

Blair, J. E., Lennette, E. H., and Truent, J. P. (1970). Manual of Clinical Microbiology. American Society for Microbiology, Bethesda, Md.

Bottone, E. J., Chester, B., Malowany, M. S., and Allerhand, J. (1974). Unusual Yersinia enterocolitica isolates not associated with mesenteric lymphadenitis. Applied Microbiology, 27, 858-861.

Carpenter, C. C. J., Barua, D., Wallace, C. K., Sack, R. B., Mitra, P. P., Werner, A. S., Duffy, T. P., Oleinick, A., Khanra, S. R., and Lewis, G. W. (1965). Clinical and physiological observations during an epidemic outbreak of non-vibrio cholera-like disease in Calcutta. Bulletin of the World Health Organization, 33,
665-671.

Chatterjee, B. D. (1975). Vibrio parahaemolyticus: $\vec{a}$ review. Journal of Communicable Diseases, 7, 107-114.

Cooper, R. G., and Brown, G. W. (1968). Plesiomona shigelloides in South Australia. Journal of Clinica Pathology, 21, 715-718.

Cowan, S. T. (1974). Cowan and Steel's Manual for th Identification of Medical Bacteria, 2nd editions Cambridge University Press, London.

Edwards, P. R., and Ewing, W. H. (1972). Identification o $\vec{\phi}$ Enterobacteriaceae, 3rd edition. Burgess Publishing $\mathrm{Co}_{2} \overrightarrow{-}$ Minneapolis.

Ewing, W. H., McWhorter, A. C., Escobar, M. R., an Lubin, A. H. (1965). Edwardsiella, a new genus of Enterobacteriaceae based on a new species, $E$. tarda International Bulletin of Bacterial Nomenclature and Taxonomy, 15, 33-38.

McIntyre, O. R., Feeley, J. C., Greenough, W. B., IIIs Benenson, A. S., Hassan, S. I., and Saad, A. (1965)? Diarrhea caused by non-cholera vibrios. American. Journal of Tropical Medicine, 14, 412-418.

Miyamoto, Y., Kato, T., Obara, Y., Akiyama, S. Takizawa, K., and Yamai, S. (1969). In vitro hemolytie characteristic of Vibrio parahaemolyticus: its close correlation with human pathogenicity. Journal of Bacteriology, 100, 1147-1149.

Mudd, S. (ed.) (1970). Infectious Agents and Hos: Reactions. Saunders, Philadelphia.

Rowe, B., Gross, R. J., and Allen, H. A. (1975). Citro bacter koseri. II. Serological and biochemical examine ation of Citrobacter koseri strains from clinical speci mens. Journal of Hygiene, 75, 129-134.

Ryan, W. J. (1976). Marine vibrios associated with super $\overrightarrow{\overline{0}}$ ficial septic lesions. Journal of Clinical Pathology, 29 1014-1015. 